\title{
Supplementation of arachidonic acid-enriched oil increases arachidonic acid contents in plasma phospholipids, but does not increase their metabolites and clinical parameters in Japanese healthy elderly individuals: a randomized controlled study
}

Saki Kakutani ${ }^{1 *}$, Yoshiyuki Ishikura², Norifumi Tateishi ${ }^{1}$, Chika Horikawa $^{1}$, Hisanori Tokuda ${ }^{1}$, Masanori Kontani ${ }^{1}$, Hiroshi Kawashima', Yutaka Sakakibara², Yoshinobu Kiso' ${ }^{1}$, Hiroshi Shibata' ${ }^{1}$ and Ikuo Morita ${ }^{3}$

\begin{abstract}
Background: The importance of arachidonic acid (ARA) among the elderly has recently gained increased attention. The effects of ARA supplementation in the elderly are not fully understood, although ARA is considered to be associated with various diseases. We investigate whether ARA supplementation to Japanese elderly subjects affects clinical parameters involved in cardiovascular, inflammatory, and allergic diseases. We also examine the levels of ARA metabolites such as prostanoids during intervention.

Methods: We conducted a randomized, double-blind and placebo-controlled parallel group intervention trial. ARAenriched oil (240 or $720 \mathrm{mg}$ ARA per day) or placebo was administered to Japanese healthy men and women aged 55-70 years for 4 weeks followed by a 4-week washout period. The fatty acid contents of plasma phospholipids, clinical parameters, and ARA metabolites were determined at baseline, 2, 4, and 8 weeks.

Results: The ARA content in plasma phospholipids in the ARA-administrated groups increased dose-dependently and was almost the same at 2 weeks and at 4 weeks. The elevated ARA content decreased to nearly baseline during a 4-week washout period. During the supplementation and washout periods, no changes were observed in eicosapentaenoic acid and docosahexaenoic acid contents. There were no changes in clinical blood parameters related to cardiovascular, inflammatory and allergic diseases. ARA supplementation did not alter the level of ARA metabolites such as urinary 11-dehydro thromboxane $B_{2}$, 2,3-dinor-6-keto prostaglandin (PG) $F_{1 \alpha}$ and 9,15-dioxo11 $\alpha$-hydroxy-13,14-dihydro-2,3,4,5-tetranor-prostan-1,20-dioic acid (tetranor-PGEM), and plasma PGE 2 and lipoxin $A_{4}$. ARA in plasma phospholipids was not correlated with ARA metabolite levels in the blood or urine.

Conclusion: These results indicate that ARA supplementation, even at a relatively high dose, does not increase ARA metabolites, and suggest that it does not induce cardiovascular, inflammatory or allergic diseases in Japanese elderly individuals.
\end{abstract}

Keywords: arachidonic acid, thromboxane $A_{2}$, prostacyclin, prostaglandin $E_{2}$, cardiovascular diseases, inflammation

* Correspondence: saki_kakutani@suntory.co.jp

'Institute for Health Care Science, Suntory Wellness Ltd., Osaka, Japan

Full list of author information is available at the end of the article 


\section{Background}

Arachidonic acid (ARA) is an n-6 essential fatty acid that is a major constituent of biomembranes. It is converted into lipid mediators that exert various physiological actions. ARA is synthesized in the body from dietary linoleic acid (LA) and additionally most adults consume $50-250 \mathrm{mg} /$ day of ARA from foodstuffs [1-3].

The consumption of ARA in breast milk is very important for infant development since the activity from LA conversion to ARA is low in infant [4]. The conversion of LA to ARA declines with age [5], and the importance of ARA supplementation among the elderly has recently gained increased attention. It has been reported that supplementation with ARA among the elderly improves cognitive response [6] and coronary flow velocity reserve [7] and some animal studies support these findings [8-11].

However, many studies show that lipid mediators derived from ARA are associated with various diseases. For example, thromboxane $\mathrm{A}_{2}\left(\mathrm{TXA}_{2}\right)$ is associated with cardiovascular diseases via its activation of thrombogenicity and vasoconstriction, whereas prostaglandin $\mathrm{E}_{2}$ $\left(\mathrm{PGE}_{2}\right)$ leads to inflammation and might enhance tumor growth [12-14]. Levels of the urinary TXA $_{2}$ metabolite, 11-dehydro $\mathrm{TXB}_{2}$, have been shown to be higher in patients with heart failure (3.4-fold), ischemic heart disease (1.4-fold) [15] and essential hypertension [16]. Plasma $\mathrm{PGE}_{2}$ levels are also high in patients with ulcerative colitis [17] and advanced periodontitis [18], and levels of its urinary metabolite, tetranor-PGEM, are epidemiologically higher in colorectal cancer [19]. The relationship between lipids mediators and diseases is speculated based on the fact that cyclooxygenase (COX) inhibitors are effective against these conditions $[14,20]$.

Many clinical trials of ARA supplementation have been done on infants [4], but there are a few reports describe the administration of ARA or ARA-containing oil to adults [21-23]. Among healthy males who consumed 1.5 g/day of ARA (as free ARA) for 50 days [21,22] or 838 mg/day of ARA for 4 weeks [23] in randomized controlled studies, platelet aggregation did not change and adverse effects did not occur. Both urinary 11-dehydro $\mathrm{TXB}_{2}$ and 2,3-dinor-6-keto $\mathrm{PGF}_{1 \alpha}$ slightly increased in the former study [22]. However, it remains unclear whether ARA intake evokes the clinical parameters in the speculated diseases in the elderly. It is also unclear whether ARA intake increases lipid mediators derived from ARA in the elderly.

The present study investigates the effects of 240 or $720 \mathrm{mg} /$ day of ARA, which is much more than that derived from food, on Japanese healthy elderly individuals. We determined clinical parameters of cardiovascular, inflammatory, and allergic diseases in blood as well as ARA content in plasma phospholipids and urinary and plasma lipid mediators. Correlations between
ARA content in plasma phospholipids and lipid mediator concentrations were also determined.

\section{Materials and methods Study design}

This randomized, double-blind and placebo-controlled parallel group intervention trial evaluated the effects of daily ARA supplementation on cardiovascular disease and/or inflammation. The Ethics Committee on Human Experimentation of Suntory Holdings Ltd. approved the study, which conformed to the principles set forth in the Declaration of Helsinki. Written informed consent was obtained from the participants of this study. Physiological parameters and blood and urine were sampled at the time of recruitment starting in August 2010. One hundred and eighteen participants were screened and randomly assigned to placebo, low-ARA or high-ARA groups. Participants received 10 gelatin-capsules containing either ARA or a placebo every morning for 4 weeks followed by a 4-week washout period. Blood and urine were sampled, a study diary was distributed and collected and dietary intake was assessed at baseline (week 0 , within 4 weeks of recruitment) and again at 2 , 4 and 8 weeks later. The fatty acid composition of the oils used in this study is shown in Table 1. The placebo

Table 1 Fatty acid composition of test capsules

\begin{tabular}{|c|c|c|c|}
\hline \multirow{2}{*}{$\begin{array}{l}\text { Fatty acids }{ }^{1} \\
(\%)\end{array}$} & \multicolumn{3}{|c|}{ Group } \\
\hline & Placebo & Low-ARA & High-ARA \\
\hline $14: 0$ & 0.0 & 0.2 & 0.5 \\
\hline $15: 0$ & 0.0 & 0.0 & 0.2 \\
\hline $16: 0$ & 12.2 & 11.9 & 11.3 \\
\hline $16: 1$ & 1.2 & 0.8 & 0.0 \\
\hline $17: 0$ & 0.0 & 0.1 & 0.3 \\
\hline $18: 0$ & 2.8 & 4.5 & 8.1 \\
\hline $18: 1$ & 72.3 & 50.3 & 6.3 \\
\hline $18: 2 n-6$ & 9.6 & 9.4 & 8.9 \\
\hline $18: 3 n-6$ & 0.0 & 0.9 & 2.6 \\
\hline $18: 3 n-3$ & 0.7 & 0.6 & 0.4 \\
\hline $20: 0$ & 0.4 & 0.6 & 0.9 \\
\hline $20: 1$ & 0.3 & 0.3 & 0.4 \\
\hline $20: 2 n-6$ & 0.0 & 0.2 & 0.7 \\
\hline $20: 3 n-6$ & 0.0 & 1.4 & 4.0 \\
\hline $20: 4 n-6$ & 0.0 & 14.2 & 42.9 \\
\hline $22: 0$ & 0.1 & 1.2 & 3.3 \\
\hline $22: 4 n-6$ & 0.0 & 0.2 & 0.5 \\
\hline $24: 0$ & 0.0 & 2.6 & 7.5 \\
\hline Others & 0.4 & 0.6 & 1.2 \\
\hline
\end{tabular}

14:0, myristic acid; 15:0, pentadecanoic acid; 16:0; palmitic acid; 16:1, palmitoleic acid; 17:0, heptadecanoic acid; 18:0, stearic acid; $18: 1$, oleic acid; 18:2n-6, linoleic acid; 18:3n-6, $\gamma$-linolenic acid; 18:3n-3, $\alpha$-linolenic acid; 20:0, eicosanoic acid; 20:1, eicosenic acid; 20:2n-6, eicosadienoic acid; 20:3n-6, dihomo- $\gamma$-linolenic acid; $20: 4 n-6$, arachidonic acid; $22: 0$, behenic acid; $22: 4 n-6$, docosatetraenoic acid; and 24:0, lignoceric acid. 
group consumed $1700 \mathrm{mg} /$ day of commercially available olive oil. The high-ARA group consumed $1700 \mathrm{mg} /$ day of an ARA-enriched edible oil derived from Mortierella alpina (SUNTGA40S; $720 \mathrm{mg} /$ day of ARA) [24]. The low-ARA group received $570 \mathrm{mg} /$ day of ARA-enriched oil and $1130 \mathrm{mg} /$ day of olive oil (240 mg/day of ARA). Blood and urine samples were obtained after an overnight fast for $>10$ hours on the morning of each assessment. Cardiovascular risk parameters included prothrombin time (PT), activated partial thromboplastin time (APTT), antithrombin III (ATIII), high-sensitivity $\mathrm{C}$-reactive protein (hs-CRP) and adiponectin. Allergic parameters included nonspecific immunoglobulin $\mathrm{E}$ (IgE) levels and eosinophils (EO). Inflammatory parameters comprised C-reactive protein (CRP), interleukin6 (IL-6) and tumor necrosis factor- $\alpha$ (TNF- $\alpha$ ) levels. Urinalysis was conducted for quantitative analysis of creatinine (Cre) and qualitative analyses of protein, glucose and urobilinogen.

\section{Participants}

Healthy men and women aged 55-70 years living in Tokyo and its environs were recruited. Exclusion criteria were as follows: allergy to gelatin or olive oil; continuous consumption of drugs or supplements that affect lipid metabolism; continuous intake of non-steroidal antiinflammatory or anti-allergic drugs; a history of serious disorders such as cardiac infarction, cerebral infarction, stroke, cancer, asthma; and clinically significant systemic diseases. Participants were randomly assigned to the three groups matched by gender, age, hs-CRP, PT and estimated ARA content (\%) in plasma phospholipids. To quickly estimate the ARA content in plasma phospholipids at the recruitment, the estimated ARA content was calculated from triglycerides (TG, mg/dL), phospholipids (PL, mg/dL) and the ARA content in total plasma fatty acids as: (ARA content in total plasma fatty acids) $\times(\mathrm{TG}$ $+\mathrm{PL}) / \mathrm{PL}$. This rough estimation is based on the fact that the ARA content is much smaller in plasma TG than in plasma PL (the ARA in plasma TG is negligiblysmall for the rough estimation), and used only for quick assignment to the three groups.

\section{Chemicals and apparatus}

We purchased 11-dehydro $\mathrm{TXB}_{2}, 9,15$-dioxo-11 $\alpha$ hydroxy-13,14-dihydro-2,3,4,5-tetranor-prostan-1,20dioic acid (tetranor-PGEM), lipoxin $\mathrm{A}_{4}\left(\mathrm{LXA}_{4}\right)$, 11-dehydro $\mathrm{TXB}_{2}$-d4, 9,15-dioxo-11 $\alpha$-hydroxy-2,3,4,5-tetranorprostan-1,20-dioic-13,13,14,14,15,15-d6 acid (tetranorPGEM-d6), and $\mathrm{LXA}_{4}$-d5 from Cayman Chemical (Ann Arbor, MI, USA). Fatty acid methyl esters were chromatographically separated and detected using an Agilent 6890 GLC system (Agilent Technologies, Santa Clara, CA, USA) equipped with a Supelco SP-2330 column (30 $\mathrm{m} \times 0.32 \mathrm{~mm} \times 0.2 \mu \mathrm{m}$, Sigma-Aldrich, St. Louis, MO, USA). Lipid mediators were chromatographically separated and detected using an Agilent 1200 HPLC system (Agilent Technologies) equipped with a Cadenza CDC18 column $(3 \mu \mathrm{m}, 2 \mathrm{~mm}$ i.d. $\times 150 \mathrm{~mm}$, Imtakt, Kyoto, Japan) and a 4000 Q TRAP with electrospray interface (AB SCIEX, Foster City, CA, USA).

\section{Fatty acid analysis}

Lipids in plasma were extracted and purified by the method of Folch et al. [25]. Fatty acid residues in lipid fractions were analyzed by the method of Sakuradani et al. [26]. In brief, each fraction was incubated with an internal standard (pentadecanoic acid) in methanolic $\mathrm{HCl}$ at $50^{\circ} \mathrm{C}$ for $3 \mathrm{~h}$ to transmethylate fatty acid residues to fatty acid methyl esters, which were extracted with $n$ hexane and analyzed by capillary gas-liquid chromatography. Plasma was directly transmethylated without extraction or fractionation when we calculated the estimated ARA content in plasma phospholipids.

\section{Analysis of urinary metabolites of lipid mediators}

Urine samples were stored at $-80^{\circ} \mathrm{C}$ for $5-41$ days before measurement of metabolites.

Urinary 11-dehydro $\mathrm{TXB}_{2}$ was measured by LC-MS/ MS. Urine samples $(0.5 \mathrm{~mL})$, to which 11 -dehydro $\mathrm{TXB}_{2}-\mathrm{d} 4$ was added as an internal standard, were diluted with $1 \mathrm{mmol} / \mathrm{L} \mathrm{HCl}$ to a final volume of approximately $3 \mathrm{~mL}$ and left for $1 \mathrm{~h}$ at room temperature. The mixtures were applied to preconditioned SPE cartridges (Empore disk cartridge C18-SD, 3M, St. Paul, MN, USA), and the cartridges were washed with 1 $\mathrm{mmol} / \mathrm{L} \mathrm{HCl}$, water and hexane. 11-Dehydro $\mathrm{TXB}_{2}$ and 11-dehydro $\mathrm{TXB}_{2}$-d4 were then eluted with $1 \mathrm{~mL}$ of hexane/ethyl acetate $(1 / 1, v / v)$. The eluates were dried by centrifugal evaporation, re-dissolved in $0.1 \mathrm{~mL}$ of acetonitrile/water/formic acid (250/750/1, v/v/v) and then transferred to brown glass vials at $10^{\circ} \mathrm{C}$. Portions of these elute $(20 \mu \mathrm{L})$ were injected into LC-MS/MS. Solvent A was $5 \mathrm{mM}$ ammonium acetate ( $\mathrm{pH}$ 5.5) and solvent B was acetonitrile. The separation was performed in an isocratic mode with $35 \%$ solvent B at a flow rate of $0.2 \mathrm{~mL} / \mathrm{min}$ and a column temperature of $40^{\circ} \mathrm{C}$. The mass spectrometer was operated in the negative ion mode. 11-Dehydro $\mathrm{TXB}_{2}$ and 11-dehydro $\mathrm{TXB}_{2}$ - $\mathrm{d} 4$ were detected in selected reaction monitoring (SRM) mode by monitoring mass transitions of $m / z 367$ $\rightarrow 305$ for 11-dehydro $\mathrm{TXB}_{2}$, and $m / z 371 \rightarrow 309$ for 11-dehydro $\mathrm{TXB}_{2}$-d4 at a collision energy of $-23 \mathrm{~V}$.

Urinary tetranor-PGEM was measured by LC-MS/MS according to the modified method of Murphey et al. [27]. Urine samples $(0.1 \mathrm{~mL})$ to which tetranor-PGEMd6 was added as an internal standard were diluted with $1 \mathrm{mmol} / \mathrm{L} \mathrm{HCl}$ to a final volume of approximately $1 \mathrm{~mL}$. 
The diluted samples were mixed with $0.5 \mathrm{~mL}$ of $\mathrm{O}$ methylhydroxylamine hydrochloride in $1.5 \mathrm{M}$ sodium acetate buffer pH $5(16 \%, \mathrm{w} / \mathrm{v})$ and left for $1 \mathrm{~h}$ at room temperature. The mixtures were applied to SPE cartridges as described above, and the cartridges were washed with $1 \mathrm{mmol} / \mathrm{L} \mathrm{HCl}$. Tetranor-PGEM and tetranor-PGEM-d6 were then eluted with $1 \mathrm{~mL}$ of ethyl acetate. The eluates were dried, re-solved and transferred as described above. Portions of these elute (20 $\mu \mathrm{L})$ were injected into LC-MS/MS. Solvent A was water/formic acid $(100 / 0.2, \mathrm{v} / \mathrm{v})$ and solvent B was acetonitrile/methanol/formic acid $(95 / 5 / 0.2, \mathrm{v} / \mathrm{v} / \mathrm{v})$. The separation was performed at a flow rate of $0.2 \mathrm{~mL} / \mathrm{min}$ and a column temperature of $60^{\circ} \mathrm{C}$ using the following linear gradient: $0-4.8 \mathrm{~min}, 30$ to $94 \%$ solvent B; 4.8 $5.75 \mathrm{~min}, 94$ to $30 \%$ solvent B; $5.75-14.8 \mathrm{~min}, 30 \%$ solvent $B$. The mass spectrometer was operated in the negative ion mode. Tetranor-PGEM and tetranorPGEM-d6 were detected in SRM mode by monitoring mass transitions at $m / z 385 \rightarrow 336$ for tetranor-PGEM, and $m / z 391 \rightarrow 342$ for tetranor-PGEM-d6 at a collision energy of $-25 \mathrm{~V}$.

Urinary 2,3-dinor-6-keto PGF $_{1 \alpha}$ was measured using an enzyme-linked immunosorbent assay (EIA) kit (2,3dinor-6-keto Prostaglandin $\mathrm{F}_{1 \alpha}$ EIA Kit, Cayman Chemical Company). Urine samples $(0.5 \mathrm{~mL})$ were diluted with $1 \mathrm{M}$ sodium citrate buffer $\mathrm{pH} 4$ to a final volume of approximately $1 \mathrm{~mL}$ and then vigorously mixed with $4 \mathrm{~mL}$ of ethyl acetate. The mixtures were separated by centrifugation and the upper phases were collected. The liquid-liquid extraction with ethyl acetate was performed three times and three upper phases of one urine sample were pooled. The pooled extracts were dried by centrifugal evaporation and re-dissolved in assay buffer for analysis.

\section{Analysis of plasma lipid mediators}

Blood samples for lipid mediators were collected in vacuum blood collection tubes containing EDTA-2Na and a final concentration of approximately $18 \mu \mathrm{M}$ of sodium indomethacin. Plasma separated within $1 \mathrm{~h}$ was then stored at $-80^{\circ} \mathrm{C}$ for $10-93$ days before measurement of mediators.

Plasma $\mathrm{PGE}_{2}$ was measured using an EIA kit (Prostaglandin $\mathrm{E}_{2}$ EIA Kit - Monoclonal, Cayman Chemical Company). Plasma samples $(1 \mathrm{~mL})$ to which $5 \mu \mathrm{L}$ of formic acid was added were diluted with $1 \mathrm{mmol} / \mathrm{L} \mathrm{HCl}$ to a final volume of approximately $3 \mathrm{~mL}$. The mixtures were applied to preconditioned SPE cartridges (BondElut C18, Agilent Technologies), and the cartridges were washed with $1 \mathrm{mmol} / \mathrm{L} \mathrm{HCl}$ and hexane. $\mathrm{PGE}_{2}$ was then eluted with $1 \mathrm{~mL}$ of ethyl acetate/methanol $(99 / 1, \mathrm{v} / \mathrm{v})$. The eluates were dried by centrifugal evaporation and re-dissolved in assay buffer for analysis.
Plasma $\mathrm{LXA}_{4}$ was measured by LC-MS/MS. Plasma samples $(1 \mathrm{~mL})$ to which $\mathrm{LXA}_{4}-\mathrm{d} 5$ was added as an internal standard were diluted with water/acetic acid $(1000 / 5, \mathrm{v} / \mathrm{v})$ to a final volume of approximately $3 \mathrm{~mL}$ and applied to preconditioned SPE cartridges (FOCUS, $20 \mathrm{mg} / 3 \mathrm{~mL}$, Agilent Technologies). The cartridges were washed with water/acetic acid $(1000 / 5, \mathrm{v} / \mathrm{v})$ and water. $\mathrm{LXA}_{4}$ and $\mathrm{LXA}_{4}-\mathrm{d} 5$ were then eluted with $1 \mathrm{~mL}$ of methanol/acetonitrile/acetic acid (600/300/1, v/v/v). The eluates were dried, re-solved and transferred as described above. Portions of these elute $(20 \mu \mathrm{L})$ were injected into LC-MS/MS. Solvent A was water/formic acid $(100 / 0.2, \mathrm{v} / \mathrm{v})$ and solvent $\mathrm{B}$ was acetonitrile/metha$\mathrm{nol} /$ formic acid $(95 / 5 / 0.2, \mathrm{v} / \mathrm{v} / \mathrm{v})$. The separation was performed at a flow rate of $0.2 \mathrm{~mL} / \mathrm{min}$ and a column temperature of $60^{\circ} \mathrm{C}$ using the following linear gradient: 0-3.75 $\mathrm{min}, 50$ to $98 \%$ solvent B; $3.75-5 \mathrm{~min}, 98 \%$ solvent B; $5-5.75 \mathrm{~min}, 98$ to $50 \%$ solvent B; $5.75-14.8 \mathrm{~min}$, $50 \%$ solvent $\mathrm{B}$. The mass spectrometer was operated in the negative ion mode. $\mathrm{LXA}_{4}$ and $\mathrm{LXA}_{4}$-d5 were detected in SRM mode by monitoring mass transitions at $m / z 351 \rightarrow 115$ for $\mathrm{LXA}_{4}$, and $m / z 356 \rightarrow 115$ for $\mathrm{LXA}_{4}-\mathrm{d} 5$ at a collision energy of $-22 \mathrm{~V}$.

\section{Dietary assessment and study diary}

Dietary habits during the preceding month were assessed using the brief self-administered diet history questionnaire (BDHQ) [28]. Dietary intake was estimated using an ad hoc computer algorithm for the BDHQ based on the Standard Tables of Food Composition in Japan [29,30]. Participants were asked to keep a record throughout the study about intake of the test capsules, the presence of symptoms, amount of exercise, amount of food and alcohol consumed and the use of medication.

\section{Statistical analysis}

Results are expressed as means \pm SD. Hs-CRP values that exceeded the upper limit of detection $(1000 \mu \mathrm{g} / \mathrm{dL})$ were rounded down to $1000 \mu \mathrm{g} / \mathrm{dL}$ and comprised of one measurement in the low-ARA group at baseline, one in the placebo group, one in the low-ARA group at 2 weeks and two in the high-ARA group at 4 weeks.

For physiological parameters, blood biochemical parameters except hs-CRP, hematological parameters, fatty acid composition of plasma phospholipids, urinary metabolites of lipid mediators and plasma lipid mediators, intra-group comparisons at 2, 4 or 8 weeks versus baseline were analyzed by repeated ANOVA and Dunnett's test using the actual values; inter-group comparisons at 2, 4, or 8 weeks were analyzed by ANOVA and the Tukey-Kramer test using the changes from baseline values. For hs-CRP, intra-group comparisons were analyzed by Friedman test and Steel test; inter-group 
comparisons were analyzed by Kruskal-Wallis test and Steel-Dwass test. For dietary intake of nutrients, intragroup comparisons at 4 weeks versus baseline were analyzed by a paired student t-test; inter-group comparisons at 4 weeks were analyzed by ANOVA and Tukey-Kramer test. For compliance rate, inter-group comparisons were analyzed by ANOVA and Tukey-Kramer test. For adverse events, inter-group comparisons were analyzed by Kruskal-Wallis test. All $p$ values were two-tailed, and a $p$ value of $<0.05$ was considered statistically significant.

\section{Results}

\section{Characteristics of the participants}

One participant in the placebo group withdrew for personal reasons and another was excluded due to meeting one of the exclusion criteria. Thus, we analyzed data generated from 64 participants in three groups (placebo, $\mathrm{n}=20$; low-ARA, $\mathrm{n}=22$; and high-ARA, $\mathrm{n}=22$ ) (Figure 1). The mean compliance rate was $>95 \%$ across the three groups and did not differ significantly among them. Side effects did not arise. The numbers of adverse events that developed were six among five participants in the placebo group, eight among six in the low-ARA group and twelve among six in the high-ARA group. None of these adverse events were severe and their frequency did not significantly differ among the groups. The adverse events were common cold (all groups), eczema (placebo and low-ARA groups), diarrhoea (high-

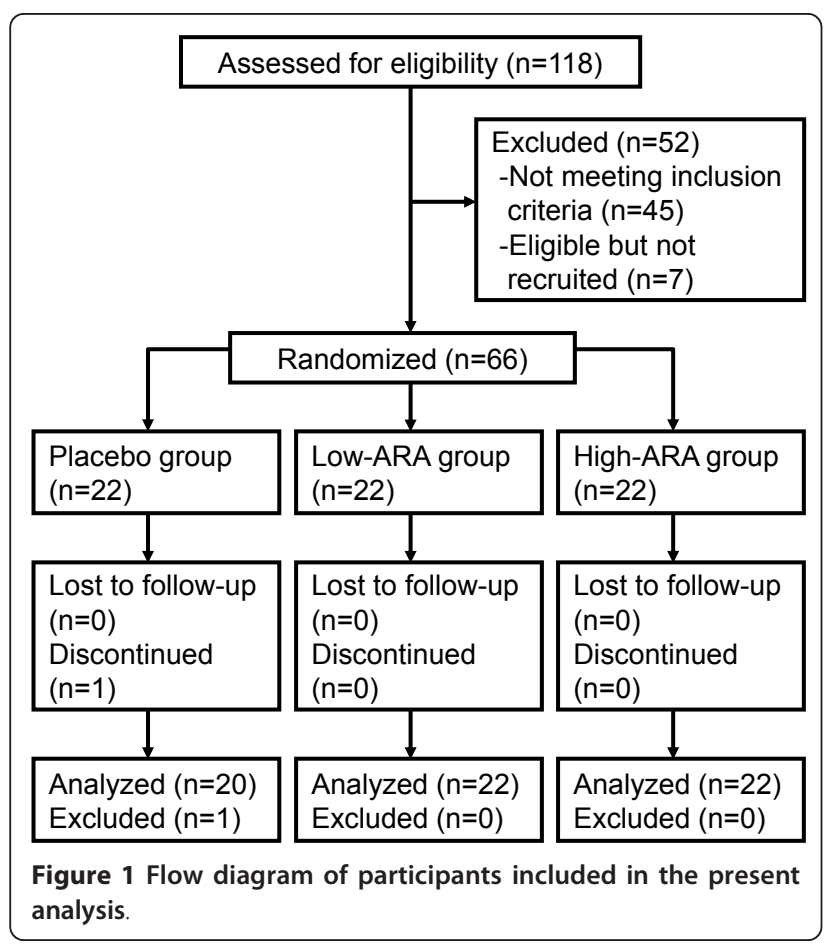

ARA group), toothache (low-ARA group), and bone fracture (placebo group).

Baseline characteristics of the three groups are shown in Table 2. All groups were balanced with respect to gender, age, BMI, alcohol consumption, smoking status and exercise. Neither hs-CRP, PT nor cardiovascular risk parameters differed significantly among the groups. The mean ARA content in plasma phospholipids ranged from $8.2-8.8 \%$ among the three groups and other polyunsaturated fatty acids also did not differ among them. Macronutrient intake during the preceding month at baseline or at 4 weeks later did not differ among the groups or at any time point (Table 3 ). The daily ARA intake derived from food ranged from 170-200 mg/day in all three groups with no significant differences. The daily intakes of DHA and EPA were 300-500 mg/day and 500-800 mg/day, respectively.

\section{Fatty acid profiles of plasma phospholipids}

The ARA content in plasma phospholipids in the highARA group increased from $8.77 \pm 1.32 \%$ (means \pm SD) at baseline to $14.02 \pm 1.50 \%$ at 2 weeks, and was almost the same at 4 weeks $(14.33 \pm 2.14 \%)$. The elevated ARA content declined almost to the initial level during

Table 2 Baseline characteristics of the participants ${ }^{1}$

\begin{tabular}{|c|c|c|c|c|}
\hline \multirow[b]{2}{*}{ Characteristics $^{2}$} & & \multicolumn{3}{|c|}{ Group } \\
\hline & & $\begin{array}{l}\text { Placebo } \\
(n=20)\end{array}$ & $\begin{array}{l}\text { Low-ARA } \\
(n=22)\end{array}$ & $\begin{array}{l}\text { High-ARA } \\
(n=22)\end{array}$ \\
\hline Gender (Female) & $\mathrm{n}$ & 12 & 13 & 12 \\
\hline Age & y & $63.1 \pm 3.8$ & $62.8 \pm 4.3$ & $62.9 \pm 4.2$ \\
\hline $\mathrm{BMI}$ & $\mathrm{kg} / \mathrm{m}^{2}$ & $21.5 \pm 2.4$ & $22.5 \pm 2.0$ & $22.5 \pm 3.1$ \\
\hline \multicolumn{5}{|c|}{ Alcohol consumption } \\
\hline Positive & $n$ & 11 & 13 & 9 \\
\hline Negative & $n$ & 9 & 9 & 13 \\
\hline \multicolumn{5}{|l|}{ Smoking status } \\
\hline Positive & $\mathrm{n}$ & 4 & 3 & 3 \\
\hline Negative & $n$ & 16 & 19 & 19 \\
\hline \multicolumn{5}{|l|}{ Exercise } \\
\hline Habitual & $n$ & 11 & 15 & 14 \\
\hline Nonhabitual & $n$ & 9 & 7 & 8 \\
\hline hs-CRP & $\mu \mathrm{g} / \mathrm{dL}$ & $113 \pm 98$ & $106 \pm 153$ & $104 \pm 116$ \\
\hline PT & $\%$ & $91.4 \pm 8.5$ & $91.4 \pm 8.6$ & $91.5 \pm 6.5$ \\
\hline $\mathrm{HbA} 1 \mathrm{c}$ & $\%$ & $4.9 \pm 0.2$ & $4.9 \pm 0.3$ & $4.9 \pm 0.4$ \\
\hline \multicolumn{5}{|l|}{ FA composition } \\
\hline $18: 2 n-6$ & $\%$ & $18.33 \pm 2.64$ & $18.91 \pm 2.16$ & $17.78 \pm 2.62$ \\
\hline $20: 4 n-6$ & $\%$ & $8.27 \pm 1.26$ & $8.61 \pm 0.92$ & $8.77 \pm 1.32$ \\
\hline $20: 5 n-3$ & $\%$ & $2.85 \pm 1.30$ & $3.17 \pm 1.42$ & $3.59 \pm 2.16$ \\
\hline $22: 6 n-3$ & $\%$ & $7.83 \pm 1.42$ & $8.10 \pm 1.27$ & $8.41 \pm 2.29$ \\
\hline
\end{tabular}

${ }^{1}$ Values are means \pm SD. No significance among the groups (ANOVA and Tukey-Kramer or Kruskal-Wallis tests).

${ }^{2}$ hs-CRP, high-sensitivity CRP; PT, prothrombin time; $\mathrm{HbA} 1 \mathrm{c}$, hemoglobin $\mathrm{A} 1 \mathrm{c}$; FA, fatty acid; $18: 2 n-6$, linoleic acid; $20: 4 n-6$, arachidonic acid; $20: 5 n-3$, eicosapentaenoic acid; 22:6n-3, docosahexaenoic acid. 
Table 3 Calculated daily nutrient intake at baseline and after four weeks of supplementation ${ }^{1}$

\begin{tabular}{|c|c|c|c|c|c|c|c|}
\hline \multirow[t]{2}{*}{ Nutrient } & & \multicolumn{3}{|c|}{ Baseline (week 0) } & \multicolumn{3}{|c|}{ Supplementation (week 4) } \\
\hline & & Placebo & Low-ARA & High-ARA & Placebo & Low-ARA & High-ARA \\
\hline Energy & $\mathrm{kcal} / \mathrm{d}$ & $1871 \pm 483$ & $1779 \pm 439$ & $2017 \pm 636$ & $1973 \pm 550$ & $1748 \pm 410$ & $1945 \pm 497$ \\
\hline Protein & $g / d$ & $73.4 \pm 21.6$ & $67.1 \pm 17.2$ & $78.0 \pm 22.2$ & $74.6 \pm 21.4$ & $68.9 \pm 17.8$ & $77.0 \pm 21.4$ \\
\hline Carbohydrate & $g / d$ & $256 \pm 68$ & $234 \pm 82$ & $260 \pm 91$ & $278 \pm 76$ & $227 \pm 63$ & $259 \pm 74$ \\
\hline Total fat & $\mathrm{g} / \mathrm{d}$ & $56.0 \pm 19.1$ & $52.8 \pm 16.6$ & $61.0 \pm 21.9$ & $56.5 \pm 22.3$ & $52.4 \pm 14.8$ & $57.5 \pm 16.8$ \\
\hline SFA & $g / d$ & $16.2 \pm 6.3$ & $14.7 \pm 5.0$ & $16.3 \pm 6.7$ & $15.5 \pm 8.1$ & $14.1 \pm 4.4$ & $15.2 \pm 5.2$ \\
\hline MUFA & $g / d$ & $19.3 \pm 7.0$ & $18.4 \pm 6.4$ & $21.8 \pm 8.2$ & $19.6 \pm 7.6$ & $18.4 \pm 5.7$ & $20.4 \pm 6.1$ \\
\hline PUFA & $g / d$ & $13.1 \pm 4.6$ & $12.7 \pm 3.6$ & $14.8 \pm 4.7$ & $13.8 \pm 4.3$ & $12.8 \pm 3.4$ & $14.1 \pm 4.0$ \\
\hline $18: 2 n-6$ & $g / d$ & $9.96 \pm 3.52$ & $9.76 \pm 2.85$ & $11.12 \pm 3.60$ & $10.59 \pm 3.34$ & $9.71 \pm 2.56$ & $10.74 \pm 3.05$ \\
\hline $20: 4 n-6$ & $\mathrm{mg} / \mathrm{d}$ & $174 \pm 56$ & $170 \pm 71$ & $199 \pm 74$ & $172 \pm 67$ & $174 \pm 73$ & $189 \pm 66$ \\
\hline $18: 3 n-3$ & $g / d$ & $1.61 \pm 0.61$ & $1.52 \pm 0.48$ & $1.79 \pm 0.62$ & $1.67 \pm 0.57$ & $1.51 \pm 0.41$ & $1.71 \pm 0.51$ \\
\hline $20: 5 n-3$ & $\mathrm{mg} / \mathrm{d}$ & $377 \pm 215$ & $315 \pm 172$ & $447 \pm 163$ & $366 \pm 197$ & $367 \pm 190$ & $399 \pm 202$ \\
\hline $22: 6 n-3$ & $\mathrm{mg} / \mathrm{d}$ & $616 \pm 323$ & $538 \pm 267$ & $729 \pm 261$ & $600 \pm 289$ & $611 \pm 301$ & $658 \pm 306$ \\
\hline
\end{tabular}

${ }^{1}$ Values are means \pm SD $(n=20$, placebo group; $n=22$, low-ARA; $n=22$, high-ARA). No significant differences between time points (Student's $t$-test) or groups (ANOVA and Tukey-Kramer test).

${ }^{2}$ SFA, saturated fatty acid; MUFA, monounsaturated fatty acid; PUFA, polyunsaturated fatty acid; 18:2n-6, linoleic acid; 20:4n-6, arachidonic acid; $18: 3 n-3, \alpha-$ linolenic acid; 20:5n-3, eicosapentaenoic acid; and 22:6n-3, docosahexaenoic acid.

the 4-week washout period $(10.00 \pm 1.39 \%)$ (Figure $2 \mathrm{~A})$. The time course of the ARA increase tended to be similar in the low-ARA group. The ARA content in the lowARA group was $8.61 \pm 0.92 \%$ at baseline, $11.30 \pm 1.55 \%$ at 2 weeks, and $11.15 \pm 1.52 \%$ at 4 weeks; the value declined during the washout period. The ARA content in the placebo group remained unchanged throughout the study.

In the high-ARA group, the LA content in plasma phospholipids inversely declined from $17.78 \pm 2.62 \%$ at baseline to $14.10 \pm 2.36 \%$ at 4 weeks and then increased almost to baseline levels during the 4 week washout period $(17.41 \pm 2.73 \%)$ (Figure $2 \mathrm{~B}$ ). The EPA and DHA contents in plasma phospholipids were unchanged throughout the study period in all groups (Figure 2C and 2D).

\section{Clinical parameters of cardiovascular diseases and inflammation}

Changes in clinical parameters associated with cardiovascular risk, allergy and inflammation are shown in Figure 3. Although some parameters the groups or time points differed significantly, all values were within the normal ranges and did not change according to ARA supplementation. Physiological, blood biochemical and hematological parameters were also within normal ranges and were unaffected by dose of ARA (Additional file 1, Table S1). Urinary findings were normal in all groups (data not shown).

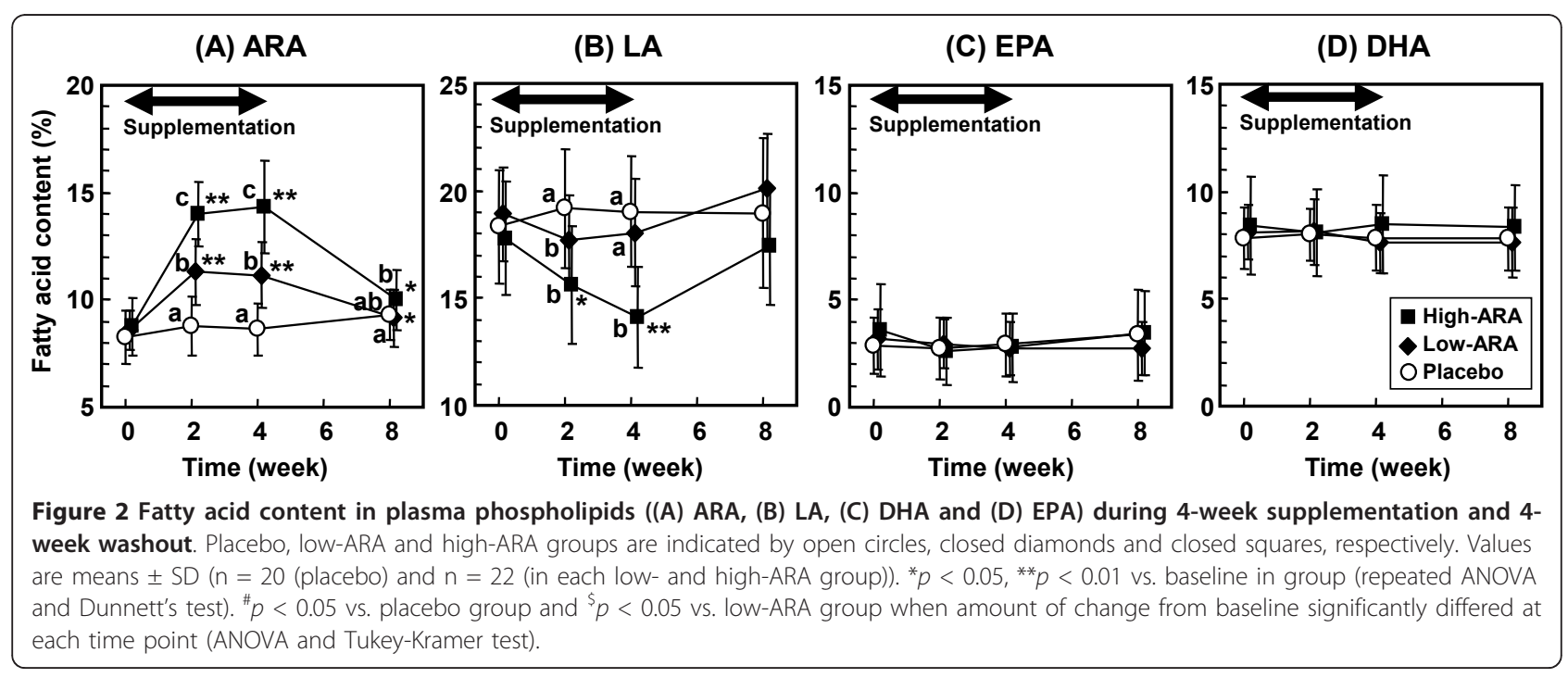




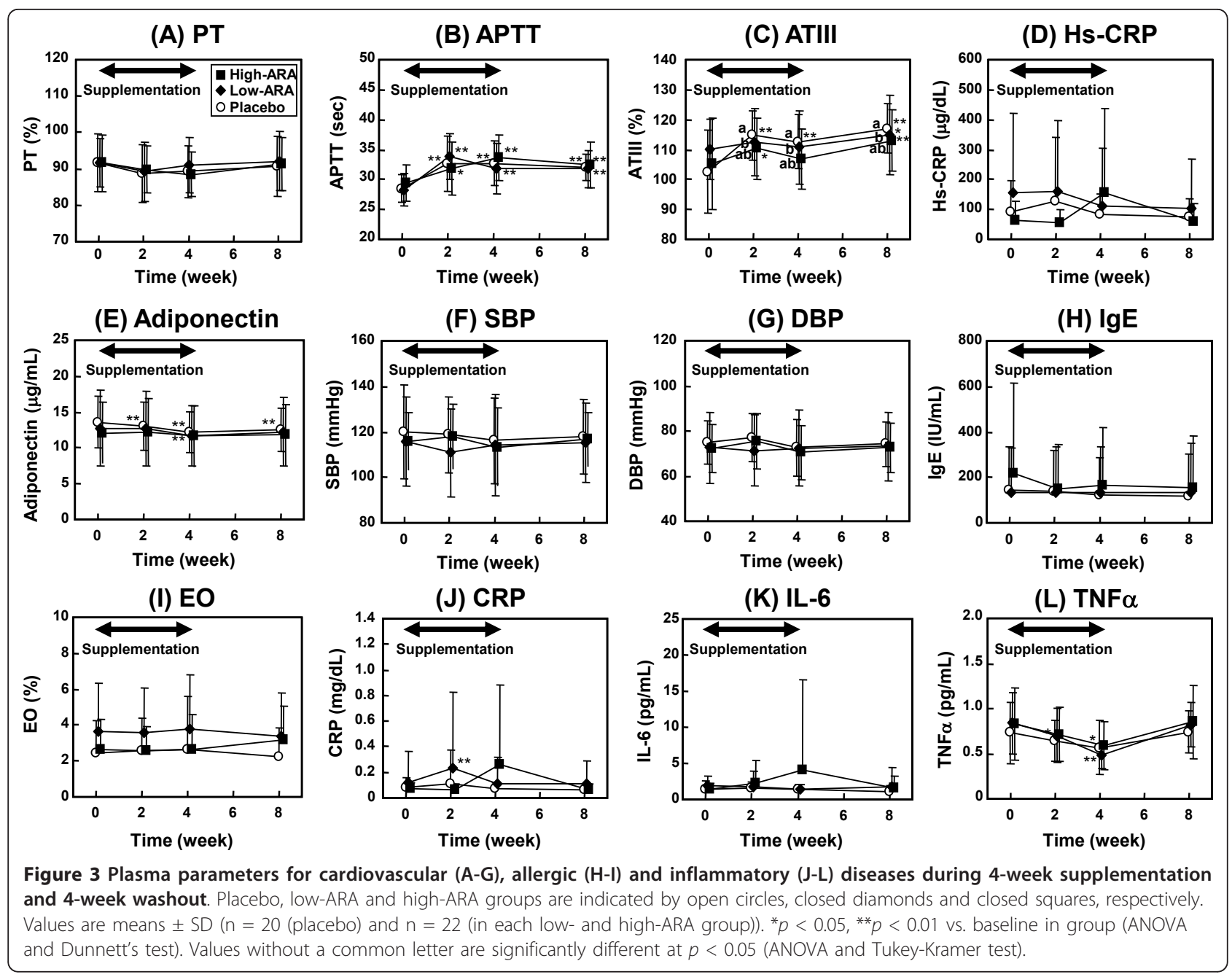

Levels of ARA metabolites in urine and blood

Concentrations of ARA metabolites in urine and blood are shown in Figure 4. Initial concentrations of urinary metabolites in the placebo, the low-ARA and the highARA groups were not significantly different. After the supplementation for 4 weeks, none of the urinary metabolites in the low-ARA and high-ARA groups significantly increased from initial levels; there were no differences among the groups at 2 and 4 weeks. At 4 weeks, the concentrations of 11-dehydro $\mathrm{TXB}_{2}, 2,3$ dinor-6-keto $\mathrm{PGF}_{1 \alpha}$ and tetranor-PGEM in the lowARA group were $0.160 \pm 0.156$ (Figure 4A), $20.6 \pm 16.7$ (Figure $4 \mathrm{~B}$ ) and $8.41 \pm 3.63 \mathrm{ng} / \mathrm{mg}$ Cre, respectively (Figure 4C); those in high-ARA group were $0.222 \pm$ 0.215 (Figure 4A), 16.4 \pm 14.1 (Figure 4B) and 16.4 \pm $14.1 \mathrm{ng} / \mathrm{mg}$ Cre, respectively (Figure 4C).

Plasma ARA-metabolites were also unchanged from the initial levels during the supplementation and showed no differences at 2 and 4 weeks among the three groups. The initial concentrations of $\mathrm{PGE}_{2}$ in the placebo, the
low-ARA and the high-ARA groups were $8.12 \pm 1.96$, $9.52 \pm 2.48$ and $10.9 \pm 3.79 \mathrm{pg} / \mathrm{mL}$, respectively (Figure 4D), and those of $\mathrm{LXA}_{4}$ were $11.9 \pm 10.8,25.4 \pm 50.0$ and $19.9 \pm 18.7 \mathrm{pg} / \mathrm{mL}$, respectively (Figure 4E), respectively. After the supplementation for 4 weeks, the concentrations of $\mathrm{PGE}_{2}$ and $\mathrm{LXA}_{4}$ in the low-ARA group were $8.37 \pm 2.40$ (Figure $4 \mathrm{C}$ ) and $20.4 \pm 17.1 \mathrm{pg} / \mathrm{mL}$, respectively (Figure 4E); those in the high-ARA group were $8.44 \pm 2.33$ (Figure $4 \mathrm{C}$ ) and $17.7 \pm 10.7 \mathrm{pg} / \mathrm{mL}$, respectively (Figure 4E).

None of the ARA metabolites measured in urine and blood measured was correlated with ARA contents in plasma phospholipids at 4 weeks of ARA supplementation (Figure 5).

\section{Discussion}

The present study clarified that in spite of the increase in ARA levels in plasma phospholipids, plasma clinical parameters of cardiovascular, inflammatory and allergic diseases and levels of ARA metabolites in urine and 


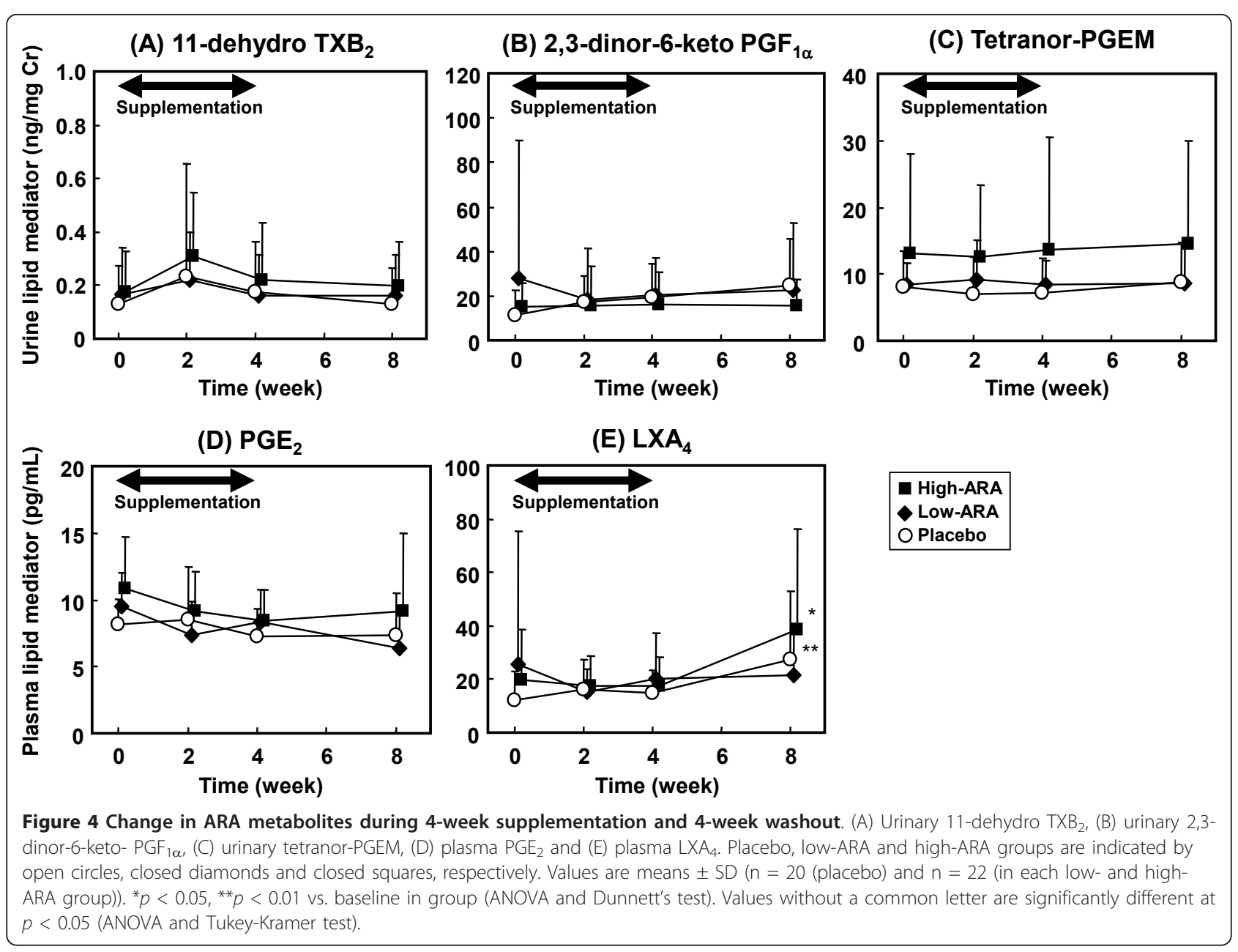

blood were not altered among the healthy elderly participants whose diet was supplemented with an ARAenriched oil (240 or $720 \mathrm{mg} /$ day ARA) for 4 weeks.

In previous studies, ARA content in plasma phospholipids increased by $0.7 \%$ in young females supplemented with $80 \mathrm{mg} /$ day of ARA for 3 weeks [31], 2.0\% in elderly males given $240 \mathrm{mg} /$ day of ARA for 4 weeks [6], and by $4.3 \%$ in adult males given $838 \mathrm{mg} /$ day of ARA for 4 weeks [23]. In the present study, supplementation with 240 and $720 \mathrm{mg} /$ day of ARA increased ARA content by $2.54 \%$ and $5.56 \%$, respectively (Figure 2 ), which was consistent with these findings. These results suggest that age or gender of participants has little effect of ARA supplementation on the increase in plasma ARA content. The results also suggest that the plasma ARA content increases dose-dependently with ARA up to at least around $800 \mathrm{mg} /$ day. The ARA content in plasma phospholipids increased at 2 weeks and was almost the same between at 2 weeks and 4 weeks. The elevated ARA content decreased to almost the initial level during the 4-week washout period regardless of an intake of 240 $\mathrm{mg} /$ day or $720 \mathrm{mg} /$ day of ARA. These results were similar to findings seen during intake of $838 \mathrm{mg} /$ day of ARA [23]. The intake of ARA caused a rapid increase in plasma ARA levels but more than 2 weeks of supplementation did not result in any further increases. This is different from DHA, because the velocity of both increases and decreases in plasma DHA content seems slower when fish oil is administered and discontinued during a washout period [32]. The changes in the other fatty acids were also characteristic since plasma DHA and EPA contents remained unchanged throughout the period. The relatively high intake of $\mathrm{DHA}+\mathrm{EPA}$ (approximately $1 \mathrm{~g} /$ day) in the present study (Table 3 ) might also have contributed to maintaining plasma DHA and EPA levels. The plasma LA content changed in parallel with the plasma ARA content (Figure 2). A previous study also noted this phenomenon [23]. Although ARA and DHA are considered to compete against each other, ARA intake does not reduce plasma DHA content, whereas intake of DHA and EPA reduces both plasma ARA and LA contents [32,33]. The 


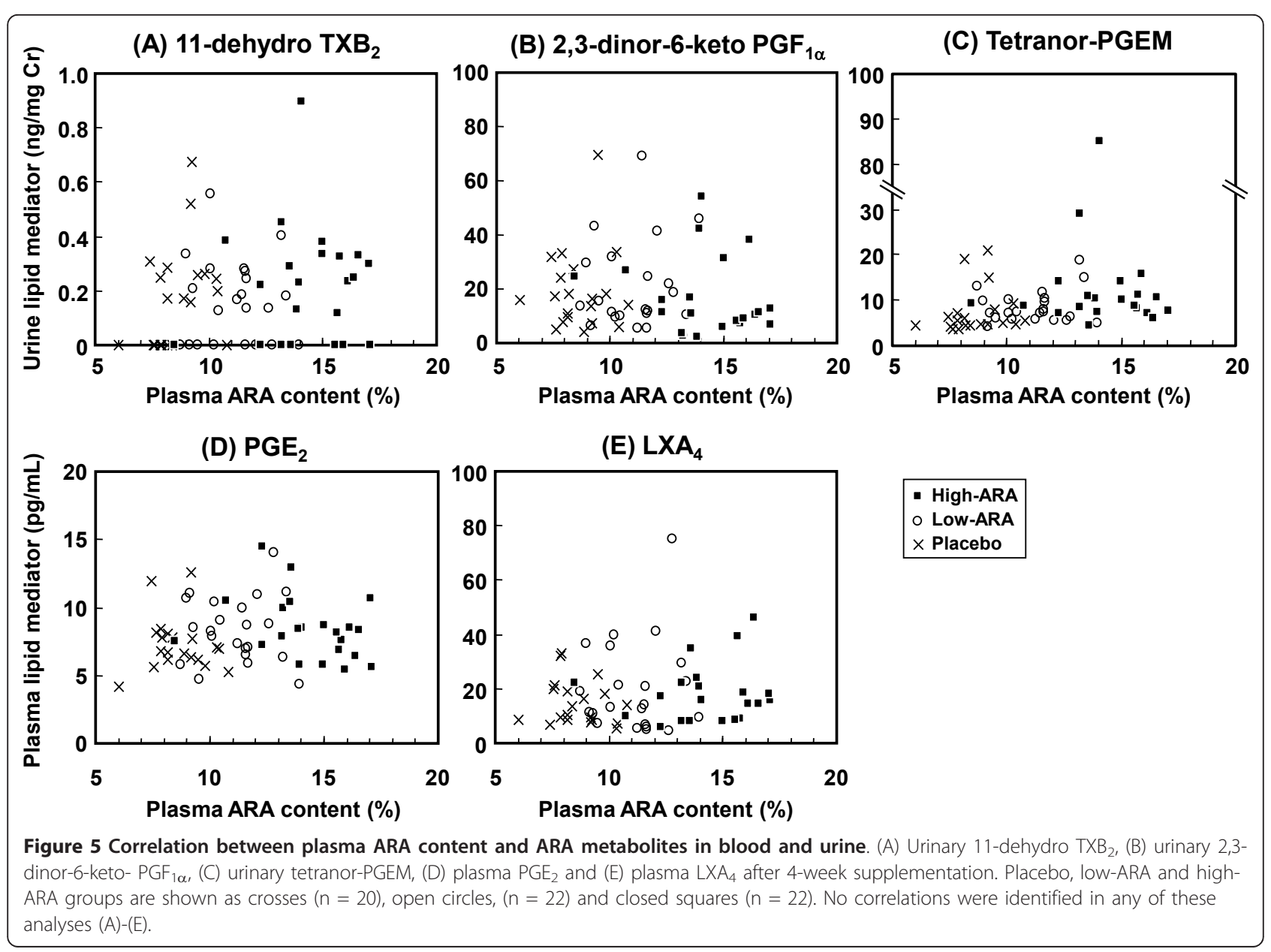

specificity of incorporation into plasma phospholipids from dietary fatty acids seems to be in the order of DHA, EPA > ARA > LA. The reason for the difference between ARA and DHA incorporation is unclear, but the specificity of some enzymes associated with acylation and/or deacylation of each fatty acid might be involved.

Platelet aggregation remains unaffected by an ARA intake of $1.5 \mathrm{~g} /$ day or $838 \mathrm{mg} /$ day in randomized controlled studies $[21,23]$. The present study found that parameters of the coagulation system (PT, APTT and ATIII) remained unaltered and within the normal range. Parameters of chronic inflammation such as plasma hsCRP, TNF $\alpha$ and IL-6, which are risk factors for cardiovascular disease, remained unchanged, as did plasma adiponectin, which is thought to reduce the risk for cardiovascular diseases. These results suggest that ARA intake does not affect the risk for cardiovascular disease. The parameters for inflammatory diseases (CRP, TNF $\alpha$ and IL-6) and allergic diseases (IgE and eosinophil) were similarly unchanged, suggesting that ARA intake does not evoke inflammatory or allergic diseases.
Furthermore, general blood biochemical and hematological parameters remained within normal ranges (Additional file 1, Table S1). Thus, ARA intake appears to be safe under the conditions described here.

In this study, we measured $\mathrm{TXA}_{2}, \mathrm{PGI}_{2}, \mathrm{PGE}_{2}$ and $\mathrm{LXA}_{4}$. TXA 2 causes platelet aggregation and vasoconstriction, which are considered to lead to cardiovascular disease, $\mathrm{PGI}_{2}$ competes against $\mathrm{TXA}_{2}$ and suppresses cardiovascular disease and $\mathrm{PGE}_{2}$ has various physiological roles, one of which is an inflammatory trigger in addition to possible involvement in cancer growth. $\mathrm{LXA}_{4}$ has effects opposite to $\mathrm{PGE}_{2}$, and reduces inflammation and cancer growth [34]. Considering their association with diseases, we estimated $\mathrm{TXA}_{2}$ and $\mathrm{PGI}_{2}$ production as urinary 11-dehydro $\mathrm{TXB}_{2}$ and 2,3-dinor6-keto $\mathrm{PGF}_{1 \alpha}$, respectively. The reported urinary concentration of 11-dehydro $\mathrm{TXB}_{2}$ is $1.489 \mathrm{ng} / \mathrm{mg}$ Cre in patients with heart failure, $0.632 \mathrm{ng} / \mathrm{mg}$ Cre in those with ischemic heart disease, $0.44 \mathrm{ng} / \mathrm{mg}$ Cre in healthy controls [15] and around $0.6 \mathrm{ng} / \mathrm{mg}$ Cre in patients with essential hypertension and retinopathy [16]. The mean concentration of 11-dehydro $\mathrm{TXB}_{2}$ throughout the 
present study was $<0.4 \mathrm{ng} / \mathrm{mg}$ Cre, which was lower than the levels in these patients and did not significantly differ among the groups. Urinary 2,3-dinor-6-keto $\mathrm{PGF}_{1 \alpha}$ was similarly unchanged and did not differ significantly among the groups. These results show that an increase in the ARA content of plasma phospholipids from $8 \%$ to $14 \%$ did not affect $\mathrm{TXA}_{2}$ and $\mathrm{PGI}_{2}$ contents. This is consistent with the finding that parameters for cardiovascular disease did not change. However, these findings seem to differ from those of a previous study in which both urinary 11-dehydro $\mathrm{TXB}_{2}$ and 2,3-dinor-6keto $\mathrm{PGF}_{1 \alpha}$ were slightly increased by intake of $1.5 \mathrm{~g}$ ARA/day for 50 days [22]. The larger dose and longer study duration might explain the discrepancies between that study and ours, but the actual reason for the difference remains unclear.

Several reports have described that plasma $\mathrm{PGE}_{2}$ increases in inflammatory diseases. For instance, the plasma $\mathrm{PGE}_{2}$ concentration increases to $>40 \mathrm{pg} / \mathrm{mL}$ in patients with ulcerative colitis [17], and to $54.5 \mathrm{pg} / \mathrm{mL}$ in patients with advanced periodontitis [18] compared with about $10 \mathrm{pg} / \mathrm{mL}$ in controls. The plasma $\mathrm{PGE}_{2}$ concentration in the present study was about $10 \mathrm{pg} / \mathrm{mL}$, which was below the values associated with inflammatory diseases. This value did not change or significantly differ throughout the study. Urinary concentrations of tetranor-PGEM, another marker of $\mathrm{PGE}_{2}$ production, are higher in patients with cancer. The reported level is $11.6 \mathrm{ng} / \mathrm{mg}$ Cre in patients with colorectal cancer and $7.0 \mathrm{ng} / \mathrm{mg}$ Cre in matched controls [19]. Another study indicated a urinary tetranor-PGEM concentration of $15.0 \mathrm{ng} / \mathrm{mg}$ Cre in patients with colorectal cancer and $7.17 \mathrm{ng} / \mathrm{mg}$ Cre in polyp-free controls [35]. The mean concentration of tetranor-PGEM in the present study was $8 \mathrm{ng} / \mathrm{mg}$ Cre in the placebo and the low-ARA group, and $14 \mathrm{ng} / \mathrm{mg}$ Cre in the high-ARA group which seems relatively higher compared with normal levels reported previously. The high level of tetranor-PGEM in the high-ARA group was due to the three participants with levels > $30 \mathrm{ng} / \mathrm{mg}$ Cre. The higher levels in these participants were not changed by ARA supplementation or during the washout period. Thus, tetranor-PGEM concentration was not significantly changed by ARA supplementation, indicating that ARA intake does not affect a candidate marker of colorectal cancer. Plasma $\mathrm{LXA}_{4}$ in the high-ARA groups was significantly increased after the washout period (Figure $4 \mathrm{E}$ ). It was considered to be unrelated to ARA supplementation because the increase was also observed in the placebo group. Plasma $\mathrm{LXA}_{4}$ level may be more variable compared to the other metabolites, but the details are unclear. The increase was slight and considered not to affect the state of the participants.
Next, we analyzed correlations between plasma ARA content and ARA metabolites concentrations after 4 weeks of ARA administration (Figure 5). Concentrations of each ARA metabolite were distributed across a wide range, although all participants were healthy volunteers. None of the values correlated with plasma ARA content or ARA dose. Several individual values were high, but these values seemed normal for these patients, because the high levels in those participants were not changed at baseline and at 2 and 8 weeks. These results indicate that the increase in plasma ARA content from $8 \%$ to $14 \%$ does not increase the production of $\mathrm{TXA}_{2}, \mathrm{PGI}_{2}$, $\mathrm{PGE}_{2}$ and $\mathrm{LXA}_{4}$. The production of lipid mediators is not determined primarily by ARA content and seems to be controlled by other factors.

Diet was assessed to ensure that dietary intake of ARA and related fatty acids did not differ among the groups or as a result of the intervention. Participants consumed 170-200 mg/day of ARA from daily meals (Table 3), which is within the normal reported range [1-3] and values did not differ among the groups or with time. The intakes of DHA and EPA were 300-500 mg/day and 500-800 mg/day, respectively, and also did not differ among the groups. Although these values are within the common range in Japan, they are much more than those in Western countries ([2], [36]). Energy and macronutrient intake did not differ among the groups (Table 3), and did not seem to affect the present data.

The effects of ARA supplementation on healthy elderly were clarified here, but studies of patients with specific diseases are needed. In summary, blood parameters of cardiovascular, inflammatory and allergic diseases, as well as urinary and plasma ARA metabolites did not change in Japanese healthy elderly participants who consumed ARA-enriched oil (240 or $720 \mathrm{mg} /$ day of ARA) for 4 weeks although plasma ARA levels significantly increased.

\section{Additional material}

Additional file 1: Supplemental Table S1. Physiological parameters and blood biochemical and hematological parameters

\footnotetext{
Author details

${ }^{1}$ Institute for Health Care Science, Suntory Wellness Ltd., Osaka, Japan. ${ }^{2}$ Safety Science Institute, Suntory Business Expert Ltd., Osaka, Japan. ${ }^{3}$ Department of Cellular Physiological Chemistry, Graduate School, Tokyo Medical and Dental University, Tokyo, Japan.

\section{Authors' contributions}

SK participated in the study design, measured lipid mediators and drafted the manuscript. YI and NT participated in the study design and acquired data. $\mathrm{CH}$ carried out the nutrition survey. HT and MK measured blood fatty acids. HK participated in the study design and drafted the manuscript. YS, YK and HS participated in the study design and helped to interpret the
} 
findings. IM participated in the study design and reviewed the manuscript. All authors read and approved the final manuscript.

\section{Competing interests}

SK, YI, NT, CH, HT, MK, HK, YS, YK and HS are employees of Suntory Wellness Ltd. or Suntory Business Expert Ltd., which is a manufacturer of foods including ARA-enriched edible oil. IM has consultancy relationships with Suntory Wellness Ltd.

Received: 6 December 2011 Accepted: 22 December 2011 Published: 22 December 2011

\section{References}

1. Linseisen J, Schulze MB, Saadatian-Elahi M, Kroke A, Miller AB, Boeing $H$ : Quantity and quality of dietary fat, carbohydrate, and fiber intake in the German EPIC cohorts. Ann Nutr Metab 2003, 47:37-46.

2. Sioen IA, Pynaert I, Matthys C, De Backer G, Van Camp J, De Henauw S: Dietary intakes and food sources of fatty acids for Belgian women, focused on n-6 and n-3 polyunsaturated fatty acids. Lipids 2006, 41:415-22.

3. Kawabata T, Hirota S, Hirayama T, Adachi N, Hagiwara C, Iwama N, Kamachi K, Araki E, Kawashima H, Kiso Y: Age-related changes of dietary intake and blood eicosapentaenoic acid, docosahexaenoic acid, and arachidonic acid levels in Japanese men and women. Prostaglandins Leukot Essent Fatty Acids 2011, 84:131-7.

4. Fleith $M$, Clandinin MT: Dietary PUFA for preterm and term infants: review of clinical studies. Crit Rev Food Sci Nutr 2005, 45:205-29.

5. Maniongui C, Blond JP, Ulmann L, Durand G, Poisson JP, Bézard J: Agerelated changes in delta 6 and delta 5 desaturase activities in rat liver microsomes. Lipids 1993, 28:291-7.

6. Ishikura Y, Ikeda G, Akimoto K, Hata M, Kusumoto A, Kidokoro A, Kontani M, Kawashima H, Kiso Y, Koga Y: Arachidonic acid supplementation decreases P300 latency and increases P300 amplitude of event-related potentials in healthy elderly men. Neuropsychobiol 2009, 60:73-9.

7. Oe H, Hozumi T, Murata E, Matsuura H, Negishi K, Matsumura Y, Iwata S, Ogawa K, Sugioka K, Takemoto Y, Shimada K, Yoshiyama M, Ishikura Y, Kiso Y, Yoshikawa J: Arachidonic acid and docosahexaenoic acid supplementation increases coronary flow velocity reserve in Japanese elderly individuals. Heart 2008, 94:316-21.

8. Kotani S, Nakazawa H, Tokimasa T, Akimoto K, Kawashima H, Toyoda-Ono Y, Kiso Y, Okaichi H, Sakakibara M: Synaptic plasticity preserved with arachidonic acid diet in aged rats. Neurosci Res 2003, 46:453-61.

9. Okaichi $Y$, Ishikura $Y$, Akimoto $K$, Kawashima H, Toyoda-Ono $Y$, Kiso $Y$, Okaichi H: Arachidonic acid improves aged rats' spatial cognition. Physiol Behav 2005, 84:617-23.

10. Fukaya T, Gondaira T, Kashiyae Y, Kotani S, Ishikura Y, Fujikawa S, Kiso Y, Sakakibara M: Arachidonic acid preserves hippocampal neuron membrane fluidity in senescent rats. Neurobiol Aging 2007, 28:1179-86.

11. Nakano D, Ishii F, Fujii K, Ishikura Y, Akimoto K, Kontani M, Kawashima H, Kiso Y, Matsumura Y: Effects of dietary arachidonic acid supplementation on age-related changes in endothelium-dependent vascular responses. J Nutr Sci Vitaminol 2007, 53:75-81.

12. Narumiya S, FitzGerald GA: Genetic and pharmacological analysis of prostanoid receptor function. J Clin Invest 2001, 108:25-30.

13. Davì G, Patrono C: Platelet activation and atherothrombosis. N Engl J Med 2007, 357:2482-94.

14. Markowitz SD: Aspirin and colon cancer-targeting prevention? N Engl J Med 2007, 356:2195-8.

15. Santilli F, Davì G, Basili S, Lattanzio S, Cavoni A, Guizzardi G, De Feudis L, Traisci G, Pettinella C, Paloscia L, Minuz P, Meneguzzi A, Ciabattoni G, Patrono C: Thromboxane and prostacyclin biosynthesis in heart failure of ischemic origin: effects of disease severity and aspirin treatment. $J$ Thromb Haemost 2010, 8:914-22.

16. Minuz P, Patrignani P, Gaino S, Seta F, Capone ML, Tacconelli S, Degan M, Faccini G, Fornasiero A, Talamini G, Tommasoli R, Arosio E, Santonastaso CL, Lechi A, Patrono C: Determinants of platelet activation in human essential hypertension. Hypertension 2004, 43:64-70.
17. Wierciŕska-Drapało A, Flisiak R, Prokopowicz D: Effects of ulcerative colitis activity on plasma and mucosal prostaglandin $E_{2}$ concentration. Prostaglandins Other Lipid Mediat 1999, 58:159-65.

18. Leibur $E_{1}$ Tuhkanen A, Pintson U, Söder PO: Prostaglandin $E_{2}$ levels in blood plasma and in crevicular fluid of advanced periodontitis patients before and after surgical therapy. Oral Dis 1999, 5:223-8.

19. Cai Q, Gao YT, Chow WH, Shu XO, Yang G, Ji BT, Wen W, Rothman N, Li HL, Morrow JD, Zheng W: Prospective study of urinary prostaglandin $E_{2}$ metabolite and colorectal cancer risk. J Clin Oncol 2006, 24:5010-6.

20. Kuliczkowski W, Witkowski A, Polonski L, Watala C, Filipiak K, Budaj A, Golanski J, Sitkiewicz D, Pregowski J, Gorski J, Zembala M, Opolski G, Huber K, Arnesen H, Kristensen SD, De Caterina R: Interindividual variability in the response to oral antiplatelet drugs: a position paper of the Working Group on antiplatelet drugs resistance appointed by the Section of Cardiovascular Interventions of the Polish Cardiac Society, endorsed by the Working Group on Thrombosis of the European Society of Cardiology. Eur Heart J 2009, 30:426-35.

21. Nelson GJ, Schmidt PC, Bartolini G, Kelley DS, Kyle D: The effect of dietary arachidonic acid on platelet function, platelet fatty acid composition, and blood coagulation in humans. Lipids 1997, 32:421-5.

22. Ferretti A, Nelson GJ, Schmidt PC, Kelley DS, Bartolini G, Flanagan VP: Increased dietary arachidonic acid enhances the synthesis of vasoactive eicosanoids in humans. Lipids 1997, 32:435-9.

23. Kusumoto A, Ishikura Y, Kawashima H, Kiso Y, Takai S, Miyazaki M: Effects of arachidonate-enriched triacylglycerol supplementation on serum fatty acids and platelet aggregation in healthy male subjects with a fish diet. Br J Nutr 2007, 98:626-35.

24. Higashiyama K, Yaguchi T, Akimoto K, Fujikawa S, Shimizu S: Effects of mineral addition on the growth morphology of and arachidonic acid production by Mortierella alpina 1S-4. J Am Oil Chem Soc 1998, 75:1815-9.

25. Folch J, Lees M, Stanley GHS: A simple method for the isolation and purification of total lipids from animal tissues. J Biol Chem 1957 226:497-509.

26. Sakuradani E, Kobayashi M, Shimizu S: $\Delta 9$-Fatty acid desaturase from arachidonic acid-producing fungus: unique gene sequence and its heterologous expression in a fungus. Eur J Biochem 1999, 260:208-216.

27. Murphey L, Williams MK, Sanchez SC, Byrne LM, Csiki I, Oates JA, Johnson DH, Morrow JD: Quantification of the major urinary metabolite of $\mathrm{PGE}_{2}$ by a liquid chromatographic/mass spectrometric assay: determination of cyclooxygenase-specific $\mathrm{PGE}_{2}$ synthesis in healthy humans and those with lung cancer. Anal Biochem 2004, 334:266-75.

28. Murakami K, Mizoue T, Sasaki S, Ohta M, Sato M, Matsushita Y, Mishima N: Dietary intake of folate, other B vitamins, and omega-3 polyunsaturated fatty acids in relation to depressive symptoms in Japanese adults. Nutrition 2008, 24:140-7.

29. Science and Technology Agency: Standard tables of food composition in Japan (in Japanese). 5th rev edition. Tokyo: Printing Bureau of the Ministry of Finance; 2005

30. Science and Technology Agency: Standard tables of food composition in Japan, fatty acids section (in Japanese). 5th rev edition. Tokyo Printing Bureau of the Ministry of Finance; 2005.

31. Hirota S, Adachi N, Gomyo T, Kawashima H, Kiso Y, Kawabata T: Low-dose arachidonic acid intake increases erythrocytes and plasma arachidonic acid in young women. Prostaglandins Leukot Essent Fatty Acids 2010, 83:83-8.

32. Cao J, Schwichtenberg KA, Hanson NQ, Tsai MY: Incorporation and clearance of omega-3 fatty acids in erythrocyte membranes and plasma phospholipids. Clin Chem 2006, 52:2265-72.

33. Mori TA, Burke V, Puddey IB, Watts GF, O'Neal DN, Best JD: Purified eicosapentaenoic and docosahexaenoic acids have differential effects on serum lipids and lipoproteins, LDL particle size, glucose, and insulin in mildly hyperlipidemic men. Am J Clin Nutr 2000, 71:1085-94.

34. Chiang N, Serhan CN, Dahlén SE, Drazen JM, Hay DW, Rovati GE, Shimizu T, Yokomizo T, Brink C: The lipoxin receptor ALX: potent ligand-specific and stereoselective actions in vivo. Pharmacol Rev 2006, 58:463-87. 
35. Johnson JC, Schmidt CR, Shrubsole MJ, Billheimer DD, Joshi PR, Morrow JD, Heslin MJ, Washington MK, Ness RM, Zheng W, Schwartz DA, Coffey RJ, Beauchamp RD, Merchant NB: Urine PGE-M: A metabolite of prostaglandin $E_{2}$ as a potential biomarker of advanced colorectal neoplasia. Clin Gastroenterol Hepatol 2006, 4:1358-65.

36. Sugano M, Hirahara F: Polyunsaturated fatty acids in the food chain in Japan. Am J Clin Nutr 2000, 71:189S-96S.

doi:10.1186/1476-511X-10-241

Cite this article as: Kakutani et al: Supplementation of arachidonic acidenriched oil increases arachidonic acid contents in plasma phospholipids, but does not increase their metabolites and clinical parameters in Japanese healthy elderly individuals: a randomized controlled study. Lipids in Health and Disease 2011 10:241.

\section{Submit your next manuscript to BioMed Central} and take full advantage of:

- Convenient online submission

- Thorough peer review

- No space constraints or color figure charges

- Immediate publication on acceptance

- Inclusion in PubMed, CAS, Scopus and Google Scholar

- Research which is freely available for redistribution

Submit your manuscript at www.biomedcentral.com/submit
C Biomed Central 